\title{
Self-Tuning Resonant Control of a Seven-Leg Back-to-Back Converter for Interfacing Variable-Speed Generators to Four-Wire Loads
}

\author{
Roberto Cárdenas, Senior Member, IEEE, Enrique Espina, Jon Clare, Senior Member, IEEE, and \\ Patrick Wheeler, Senior Member, IEEE
}

\begin{abstract}
This paper considers the control of a sevenleg back-to-back voltage source inverter arrangement, feeding a four-wire load from a three-phase permanentmagnet synchronous generator (PMSG) operating at variable speed. The PMSG is controlled using a sensorless model reference adaptive system to obtain the rotor position angle. The seven-leg converter is regulated using resonant controllers at the load side and self-tuning resonant controllers at the generator side. The control system is augmented by a feedforward compensation algorithm that improves the dynamic performance during transients. Experimental results, which are obtained from a prototype, are presented and discussed.
\end{abstract}

Index Terms-AC-AC power conversion, converters, power generation control, variable-speed generation.

\section{INTRODUCTION}

V ARIABLE-SPEED operation of generation systems has several advantages, which are well reported in the literature. For instance, more energy captured in wind generators [1]; higher efficiency of diesel engines, which can be operated at the optimum power/fuel consumption ratio [2]; less stress in the mechanical components; smaller portable generation systems [3]; etc. To connect a four-wire load (e.g., an off-grid residential load) to a three-phase variable-speed generator, several power converter topologies are feasible [4]-[8]. For instance, a conventional three-leg back-to-back voltage source converter connected to a $\Delta$-Y transformer can be used. The starconnected secondary of the transformer is then used to allow the circulation of zero-sequence current through the load. However, this is a bulky solution with a low-power density.

Manuscript received January 2, 2014; revised May 7, 2014, September 30, 2014, and January 7, 2015; accepted January 26, 2015. Date of publication March 9, 2015; date of current version May 15, 2015. This work was supported in part by Fondecyt Chile under Contract 1140337 and in part by the Advanced Centre for Electrical and Electronic Engineering, Basal Project FB0008.

R. Cárdenas and E. Espina are with the Department of Electrical Engineering, University of Chile, Santiago 8370451, Chile (e-mail: rcd@ieee.org).

J. Clare and P. Wheeler are with the Department of Electrical and Electronic Engineering, The University of Nottingham, Nottingham, NG7 2RD, U.K. (e-mail: jon.clare@ nottingham.ac.uk).

Color versions of one or more of the figures in this paper are available online at http://ieeexplore.iee.org.

Digital Object Identifier 10.1109/TIE.2015.2409803
Another alternative is to use a conventional back-to-back converter with the neutral point of the load connected to the middle of a split capacitor bank in the dc-link. The main problem of this approach is that relatively large capacitors are required to minimize the ripple [8]. A different topology is presented in [7], where a four-leg matrix converter is proposed to feed the output load. This is a good solution if a compact generation system with a high-power density is required. However, there are also some problems with the matrix topology, which have been reported in the literature. For instance, matrix converters do not have boost capability [4]; therefore low-speed operation of the generator is not feasible if constant load voltage is required. Another problem is produced when the generation system feeds unbalanced/nonlinear loads. In this case, because of the lack of a dc capacitor bank, pulsations in the instantaneous output power produce harmonic distortion in the input current [6].

In this paper, the application of a seven-leg back-to-back voltage-source pulsewidth-modulation (PWM) converter is proposed with a three-leg machine-side converter (MSC) and a four-leg load-side converter (LSC), as shown in Fig. 1. Both converters are controlled using space vector modulation algorithms and resonant controllers (RCs).

RCs have been selected in this application because they have several advantages in four-wire applications. For example, they provide the capability to control zero-sequence currents and voltages [5]-[7] (which do not exist in signals obtained by conventional $\alpha-\beta$ and $d-q$ transformations) and they also allow straightforward implementation of power factor control at the generator side (as discussed in Section III-A). Additionally, RCs provide a simple approach to eliminate waveform distortion using cascade controllers [9]-[14]. Moreover, in this paper, a feedforward compensation algorithm is proposed (see Fig. 1), which is more conveniently implemented when both sides of the seven-leg converter are controlled using resonant controllers.

In this paper, the LSC output is controlled to operate at a constant $\omega_{e}^{*}$, corresponding to an electrical frequency of $50 \mathrm{~Hz}$. Therefore, the resonant controllers of the LSC are tuned to operate at fixed frequencies, and they have to regulate the positive-, negative-, and zero-sequence load-voltage components. When nonlinear loads are fed by the LSC, waveform distortion has to 


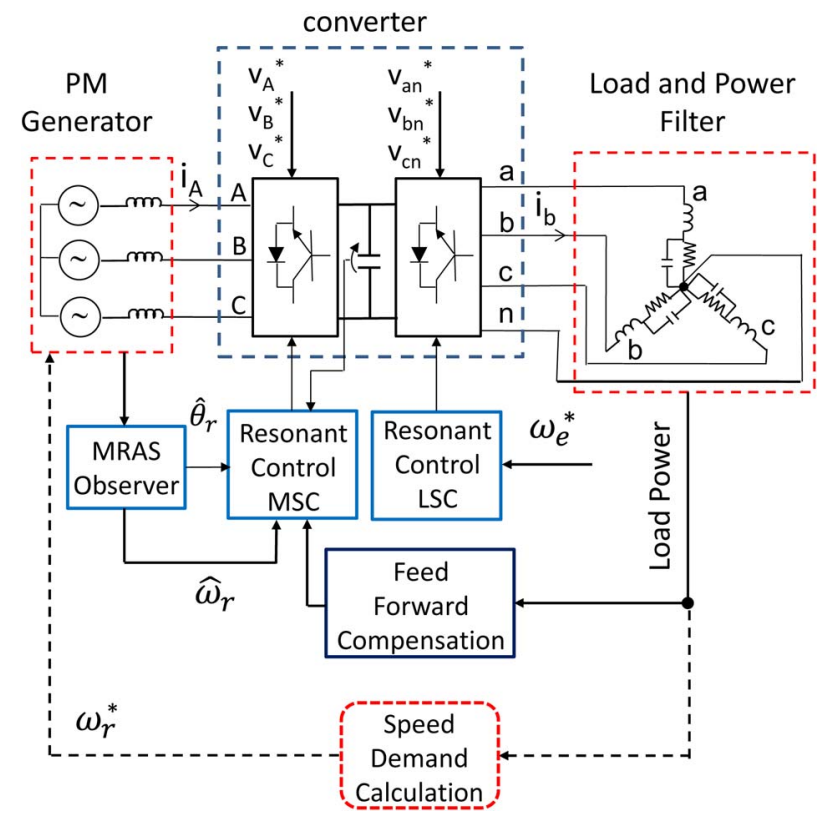

Fig. 1. Proposed seven-leg variable-speed generation system.

be eliminated also using RCs. At the MSC side, the generator output frequency varies with rotational speed. Therefore, a resonant controller is proposed, which has a frequency adaptive (self-tuning) structure, designed to obtain a good dynamic performance over the whole operating range.

In Fig. 1, a speed demand calculation block is required to adaptively change the speed, according to some control law, e.g., to reduce the fuel consumption in a diesel-based generation system, to increase the performance of a microhydro system, or to improve the energy capture in a wind energy conversion system. The control system proposed in this work has been designed to operate across the whole speed range, and the calculation/regulation of the optimal rotational speed is considered outside the scope of this paper.

The contribution of this work can be summarized as follows.

- To the best of our knowledge, this is the first paper where a variable-speed generator is interfaced by a sevenleg back-to-back voltage source inverter (VSI) to a fourwire load. The power converter topology presented in this paper can be applied to variable-speed diesel systems [15], low voltage microgrids [16]-[18], wind-diesel hybrid systems [2], utility power supplies [3], etc. In general, this topology can be used in any application where a variable-speed $3 \phi$ generator has to be interfaced with a four-wire load/grid.

- A new methodology for the design of a self-tuning RC, capable of operating over a wide-frequency range, is presented. The RC is designed in the $z$-domain to avoid the problems related with the bilinear transform or other discretization methods [19]. This design methodology can be advantageously used for grid connected power converters, [20], [21], droop-controlled converters for microgrids, and variable-speed machines [22]. The design methodology presented in this paper is certainly superior to that conventionally used to implement the "PR controller" reported in the literature [23].

- A novel feedforward compensation algorithm is analyzed and presented. The feedforward term compensates the perturbations produced by fast variations of an unbalanced linear/nonlinear load on the dc-link voltage. This feedforward compensation method can be used in other applications where high dynamic response (in the presence of power oscillations produced by unbalanced signals) is required. For instance, in conventional threeleg back to back converters, [1] and even single-phase systems.

- Small-signal models are presented, describing the dynamics of the dc link, power balance equation, dynamics of the PMSG, etc. These small-signal models consider the effect of nonlinear loads and can be used to design the controllers using conventional linear control tools. The linearized models presented in this work can be extended to other applications where power converters are used to feed nonlinear unbalanced loads.

The remainder of this paper is organized as follows. Section II briefly discusses the sensorless control system; In Section III the self-tuning resonant control system is analyzed; the load-side resonant control is very briefly presented in Section IV. Section V discusses the feedforward algorithm and Section VI presents results from an experimental prototype. Finally, Section VII discusses the conclusions from this paper. Parameters of the experimental rig are presented in the Appendix.

\section{SEnSORLESS CONTROL}

Later, in Section III, it is shown that for the implementation of the self-tuning resonant controller, the rotor position $\left(\theta_{r}\right)$ and rotational speed $\left(\omega_{r}\right)$ of the permanent-magnet synchronous generator (PMSG) are required. In this paper, $\theta_{r}$ and $\omega_{r}$ are estimated using a sensorless model reference adaptive system (MRAS) observer. Such systems have been extensively discussed in the literature before [24]-[27]; thus, only a brief discussion is provided here for completeness.

The MRAS observer is based on a reference model and an adaptive model [26], [27], [29]. The reference model is obtained as

$$
\underline{\psi}_{s}=\int\left(\underline{v}_{s}-R_{s} \underline{i}_{s}\right) d t
$$

where $\underline{\psi}_{s}$ is the stator flux, $\underline{v}_{s}$ is the stator voltage, $\underline{i}_{s}$ is the stator current and $R_{s}$ is the stator resistance $(\approx 0.2 \Omega)$.

Unlike motors, PMSG are not expected to operate at very low rotational speeds. As stated in Section III-C it is assumed in this work that the PMSG is operating between 500 and $2000 \mathrm{r} / \mathrm{min}$ $\left(0.25 \omega_{n}\right.$ to $\left.\omega_{n}\right)$. Therefore, even at $500 \mathrm{r} / \mathrm{min}$, the voltage $\underline{v}_{s}$ is relatively large compared with the small voltage drop variations produced by changes in $R_{s}$ with temperature [see (11)].

For instance, if the PMSG winding temperature varies from $20{ }^{\circ} \mathrm{C}$ to the maximum value of $140^{\circ} \mathrm{C}$, the stator resistance will change from $R_{s} \approx 0.2 \Omega$ to a $R_{s} \approx 0.294 \Omega$ (assuming 
a temperature coefficient $\alpha=0.00393 \Omega /{ }^{\circ} \mathrm{C}$ for the copper windings). Therefore, the resistive voltage drop will change from 3 to $4.4 \mathrm{~V}$ at rated current (i.e., $\Delta \mathrm{V} \approx 1.4 \mathrm{~V}$ ). Hence, even for the extreme case of rated current, minimum speed and the maximum allowable temperature rise, the change in resistive voltage drop is less than $5 \%$ of the phase voltage. Moreover, as reported in [29], for permanent-magnet machines the stability of MRAS-based sensorless control loops is not compromised by stator resistance variation.

The adaptive model is obtained using

$$
\widehat{\widehat{\psi}}_{s}=L_{s} \underline{i}_{s}+\psi_{m} e^{j \widehat{\theta}_{r}}
$$

where the superscript " $\wedge$ " indicates an estimated variable. In (2) $L_{s}$ is the stator inductance and $\underline{\psi}_{m}=\psi_{m} r e^{j \widehat{\theta}_{r}}$ is the estimated rotor flux. A smooth air-gap permanent-magnet machine is used in this work (i.e., $L_{d}=L_{q}=L_{s}$ ).

The error between the stator flux estimated by the adaptive model and that obtained from (1) is defined as

$$
\varepsilon=\left|\underline{\psi}_{s} \otimes \underline{\psi}_{s}\right|=\left|\psi_{s \beta} \widehat{\psi}_{s \alpha}-\psi_{s \alpha} \widehat{\psi}_{s \beta}\right|=\left|\underline{\psi}_{s}\right|\left|\underline{\hat{\psi}}_{s}\right| \sin (\theta)
$$

In (3) the symbol $\otimes$ represents cross-product and $\theta$ is the phase angle between the vectors $\underline{\psi}_{S}$ and $\widehat{\psi}_{S}$. The advantages of using cross product for the calculation of $\varepsilon$ are discussed in [30].

Unlike induction machines, in a PMSG, there is no slip velocity (i.e., $\omega_{\text {slip }}=0$ ) and the rotational speed is equal to the stator electrical frequency. Therefore, the speed can be correctly estimated from the frequency of the electrical signals, even if the stator resistance is affected by temperature variations. This is also concluded by inspecting (2) and (3) and a rigorous mathematic demonstration is presented in [29].

However, because the error $\varepsilon$ is defined as the cross product between $\underline{\psi}_{S}$ and $\widehat{\psi}_{S}$ [see (3)], the rotor position angle $\widehat{\theta}_{r}$ can be incorrectly estimated if the phase angle of the stator flux $\psi_{s}$ [obtained from (1)] is affected by large stator resistance variations. Nevertheless, as discussed before, for the speed operating range, the variation in the stator resistance voltage drop, due to temperature effects, is relatively small compared with the PMSG internal voltage [see Fig. 2(a)]. Moreover, in this work, the generating system is designed to operate with a power factor close to unity. Hence, the position error in $\psi_{s}$ is further reduced considering that $\underline{v}_{s}$ and $-R_{s} \underline{i}_{s}$ [see (1)] have almost identical phase. This is depicted in Fig. 2(a), where the calculation of the vectors $\underline{v}_{s}-R_{s} \underline{i}_{s}$ and $\underline{v}_{s}-\left(R_{s}+\Delta R_{s}\right) \underline{i}_{s}$ is shown. If the angle $\phi \approx 0$ (corresponding to close to unity power factor operation of the PMSG), then the phase shift between both vectors is also zero. Notice that Fig. 2(a) is not drawn to scale and the voltage drops $R_{s} \underline{i}_{s}$ and $\Delta R_{s} \underline{i}_{s}$ have been magnified in that figure.

If the PMSG is utilized at an operating point where the effect of the stator resistance variation is no longer negligible, then the implementation of online identification methods could be required. For instance, the PMSG parameter identification method reported in [16] based on adaptive observers, or the sliding-mode observer proposed in [31]. Alternatively, some of the methods proposed for stator resistance identification in

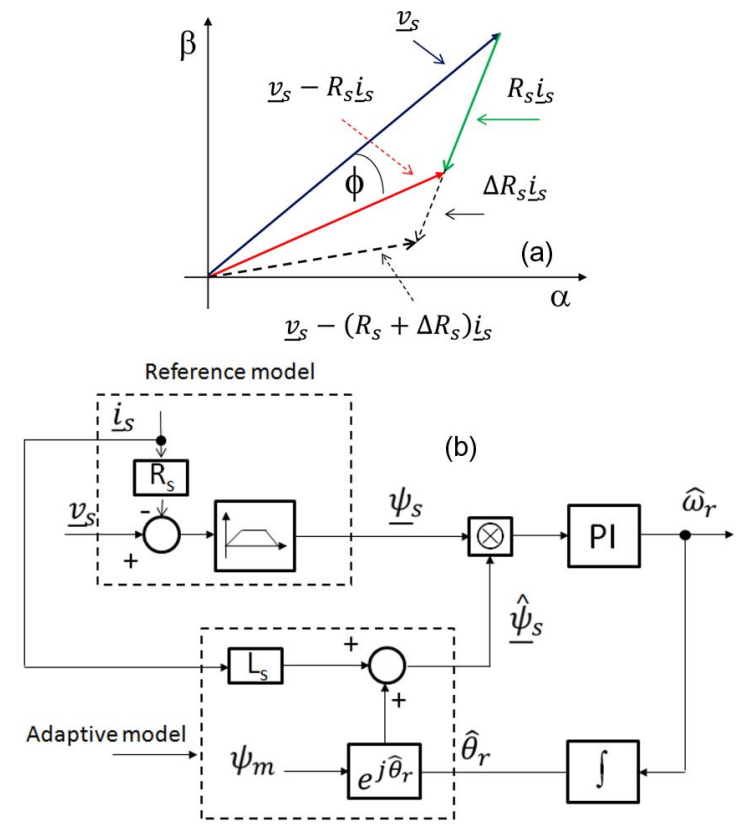

Fig. 2. (a) Phasor diagram showing the calculation of the vectors $\underline{v}_{s}-$ $R_{s} \underline{i}_{s}$ and $\underline{v}_{s}-\left(R_{s}+\Delta R_{s} \underline{i}_{s}\right)$. (b) Proposed MRAS observer.

induction machines, e.g., the P-based MRAS observer reported in [32] could be modified for $R_{s}$ identification in PMSGs.

The MRAS observer used in this paper is shown in Fig. 2(b). To avoid the drift produced by integrating dc signals, the reference stator flux $\underline{\psi}_{s}$ is calculated using a bandpass filter, instead of a pure integrator. The cross-product is calculated using the $\alpha-\beta$ components of (1) and (2). In Fig. 2(b) a proportional-integral (PI) controller is used to drive the error of (3) to zero, by adjusting the position of the magnetic flux $\underline{\psi}_{m}$.

In most of the applications related to variable-speed generation of electrical energy (e.g., wind energy systems, diesel generation, etc.), the changes in rotational speed are relatively slow, due to the inertia of the prime-mover. Therefore, to design the PI controller of Fig. 2(b), a simplified small-signal model can be used, similar to that discussed in [24].

Using the parameters of the PMSG and experimental rig (see the Appendix), the MRAS has been designed for a bandwidth of about $20 \mathrm{~Hz}$.

\section{Self-tuning Resonant Control of the MSC}

\section{A. Proposed Control System for the MSC}

The position angle $\widehat{\theta}_{r}$ is estimated from the MRAS observer of Fig. 2. Because $\widehat{\theta}_{r}$ corresponds to the flux vector $\underline{\psi}_{m}$ angle, (see Fig. 3), the position of the PMSG machine internal voltage $\widehat{\theta}_{M}$ is estimated as

$$
\widehat{\theta}_{M}=\widehat{\theta}_{r}+\frac{\pi}{2}
$$

Fig. 3 shows the proposed control system for the MSC. A PI controller, whose output is the current $i_{P}$, regulates the dc-link voltage of the back-to-back converter. An additional term from a feedforward compensation algorithm (see $i_{\mathrm{ff}}$ in Fig. 3) can 


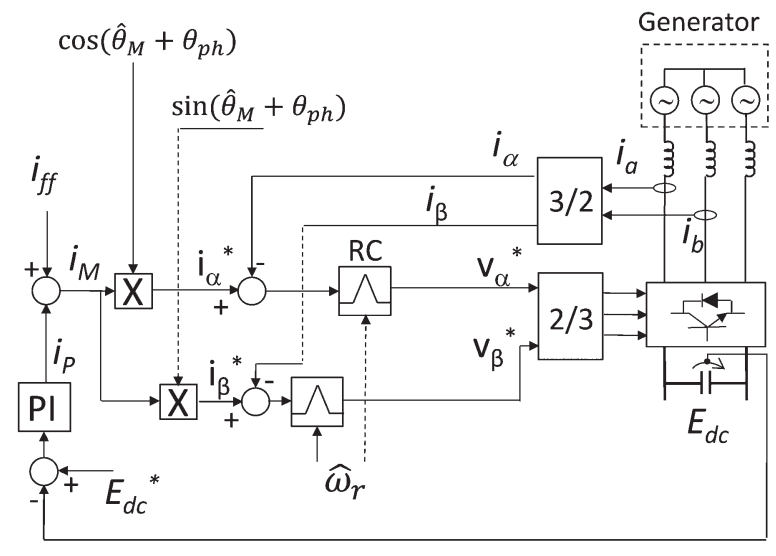

Fig. 3. Generator-side control system.

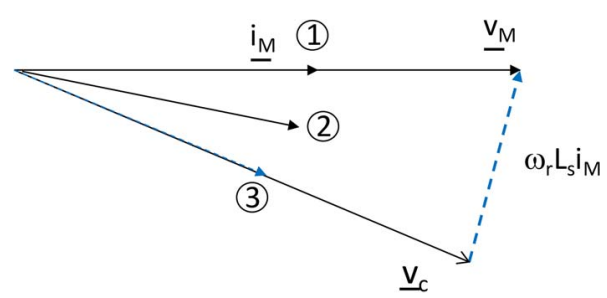

Fig. 4. Phasor diagram corresponding to the input stage.

be used to improve the dynamic performance of the dc-link voltage. This is further discussed in Section V.

In order to operate the generator with unity displacement factor, the reference currents required are

$$
\begin{aligned}
& i_{\alpha}^{*}=i_{M} \cos \left(\widehat{\theta}_{M}\right) \\
& i_{\beta}^{*}=i_{M} \sin \left(\widehat{\theta}_{M}\right) .
\end{aligned}
$$

It is also possible to introduce a phase shift angle $\theta_{\mathrm{ph}}$ between the voltage and stator current of the PMSG. For instance, three alternatives to obtain $\theta_{\mathrm{ph}}$ have been presented in the literature [25], [33] (see the phasor diagram of Fig. 4). Option 1 operates the PMSG at unity power factor, maximizing the power transfer from the PMSG to the load [25], with the MSC providing the reactive power required by the inductance $L_{s}$. Option 3 operates the MSC at unity power factor with the required phase angle $\theta_{\mathrm{ph}}$ calculated by setting $\underline{v}_{M} \approx \omega_{r} \underline{\psi}_{m}$ yielding

$$
\theta_{\mathrm{ph}} \approx-\sin ^{-1}\left(\frac{L_{s}}{\psi_{m}}\left|\underline{i}_{M}\right|\right) .
$$

Option 2 attempts to reduce saturation and obtain a compromise between the converter rating and the generator rating [33], by locating the current midway between the voltage vectors $\underline{v}_{M}$ and $\underline{v}_{c}$ with $\theta_{\mathrm{ph}}$ set to half the value of (6). The control system proposed in this work could be used to implement any of these power factor control strategies.

\section{B. Design of the DC-Link Control System}

As discussed before, the machine stator current magnitude is controlled using a PI controller augmented by a feedforward

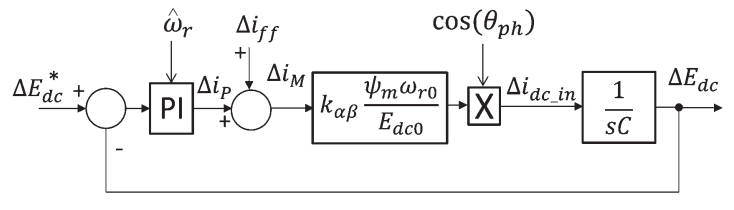

Fig. 5. Control system for the regulation of the dc-link voltage.

compensation term (see $i_{\mathrm{ff}}$ in Fig. 3 ). The design of the PI controller is discussed in the following. The feedforward algorithm is discussed in Section V.

Neglecting the MSC losses, the power supplied by the PMSG is equal to that supplied by the MSC to the dc link. Therefore, the following expression can be written:

$$
E_{\mathrm{dc}} i_{\mathrm{dc} \_ \text {in }}=k_{\alpha \beta}\left(v_{M \alpha} i_{M \alpha}+v_{M \beta} i_{M \beta}\right)
$$

where $i_{\mathrm{dc} \_ \text {in }}$ is the dc current on the generator side and $k_{\alpha \beta}$ is dependent on the $\alpha-\beta$ transformation being used. Using the angle $\theta_{\mathrm{ph}}$, then (7) can be written as

$$
E_{\mathrm{dc}} i_{\mathrm{dc} \_ \text {in }}=k_{\alpha \beta} i_{M} v_{M} \cos \left(\theta_{\mathrm{ph}}\right)
$$

where $v_{M}$ and $i_{M}$ are the magnitudes of the generator voltage and current vector, respectively. For a PMSG $v_{M} \approx \psi_{m} \omega_{r}$. Therefore, the dc-link current $i_{\mathrm{dc} \_ \text {in }}$ is obtained as

$$
i_{\text {dc_in }}=k_{\alpha \beta} \frac{\omega_{r} \psi_{m}}{E_{\mathrm{dc}}} i_{M} \cos \left(\theta_{\mathrm{ph}}\right) .
$$

Linearizing the system about an operating point indicated by the subscript " 0 " yields

$$
\begin{aligned}
\Delta i_{\mathrm{dc} \_ \text {in }}= & k_{\alpha \beta} \psi_{m} \cos \left(\theta_{\mathrm{ph}}\right) \\
& \times\left[\frac{\omega_{r 0}}{E_{\mathrm{dc} 0}} \Delta i_{M}+\frac{i_{M 0}}{E_{\mathrm{dc} 0}} \Delta \omega_{r}-\frac{\omega_{r 0} i_{M 0}}{E_{\mathrm{dc} 0}^{2}} \Delta E_{\mathrm{dc}}\right] .
\end{aligned}
$$

As discussed before, in this work, it is assumed that the PMSG speed changes slowly, therefore the term $\Delta \omega_{r}$ can be neglected when the dynamics of the current $i_{M}$ are considered. Moreover, the variation $\Delta i_{\mathrm{dc} \_ \text {in }}$ produced by $\Delta E_{\mathrm{dc}}$ [last term in (10)], is compensated by an identical variation in $\Delta i_{\mathrm{dc}_{\mathrm{o}} \text { ut }}$ at the LSC side. This is due to the fact that the LSC is operating with constant power output and the load voltage is regulated with a fast dynamic response. Therefore, neglecting $\Delta \omega_{r}, \Delta E_{\mathrm{dc}}$ the current $\Delta i_{\mathrm{dc}}$ circulating through the dc-link capacitors is obtained as

$$
\Delta i_{\mathrm{dc}}=k_{\alpha \beta} \cos \left(\theta_{\mathrm{ph}}\right) \frac{\omega_{r o} \psi_{m}}{E_{\mathrm{dco}}} \Delta i_{M} .
$$

The transfer function of (11) and the small-signal model of Fig. 5 can be used for the design of the dc-link PI controller. Notice that the gain of the controller is a function of $\omega_{r}$. This allows the system to remain tuned in spite of speed variations [see (11)]. Moreover, even if the relatively small losses of the 


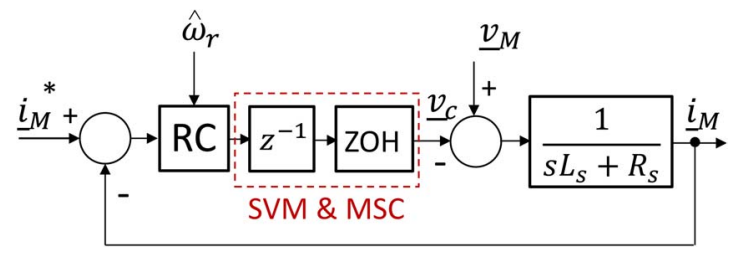

Fig. 6. Resonant control system for the generator side converter

system [not considered in (7)] affect the gain of (11), linear control tools can be used to design a robust PI controller whose performance is little affected by small variations of this gain.

Notice that in (9)-(11), it is assumed that the feedforward current $\left(\Delta i_{\text {iff }}\right)$ is an external perturbation. Therefore, it can be considered that $\Delta i_{p}=\Delta i_{M}$ because the closed loop poles of the dc-link voltage control system are not affected by the feedforward compensation algorithm.

\section{Generator-Side Resonant Control System}

Resonant Controllers are based on the internal model principle, and they can be used in control systems with sinusoidal reference signals [5]-[7], [9], [10], [23], [34]-[36]. One of the advantages is that a single $\mathrm{RC}$ per phase can be used to regulate the positive-, negative-, and zero-sequence signals at the LSC. In this application, RCs are used to regulate the stator current in the PMSG and the voltage of the load fed by the LSC.

Resonant controllers have been discussed in the literature; however, RCs are generally used in applications where variations in the resonant frequency are small, e.g for grid-connected converters [10], [23], [34]. However, in the proposed system, the PMSG can operate over a wide speed range (e.g., $500 \mathrm{r} / \mathrm{min}$ to $\approx 2000 \mathrm{r} / \mathrm{min}$ ). Therefore, the coefficients of the resonant control system have to be adjusted according to the stator frequency variation, in order to operate with a suitable bandwidth and phase margin over the whole speed range. This type of controller is usually called a "self-tuning" resonant controller in the literature [22], [37], [38]. To the best of our knowledge, [37] is the only paper where a self-tuning RC is designed and experimentally tested for a system where operation over a wide-frequency range is considered. However, in contrast to the approach proposed here, the methodology reported in [37] proposes to locate the resonant poles in a position where the PMSG stator currents cannot be regulated with low or zero steady-state error. In this paper, digital design in the $z$-plane is proposed, avoiding the problems associated with the conventional implementation of resonant controllers based on discretization methods [19].

The stator current of the PMSG is obtained from

$$
\underline{v}_{M}=R_{s} \underline{i}_{M}+L_{s} \frac{d \underline{i}_{M}}{d t}+\underline{v}_{c}
$$

where $\underline{v}_{c}$ is the MSC voltage vector. Using (11) and (12) the control loop shown in Fig. 6 is proposed where the reference current vector $\left(i_{M}^{*}\right)$ is derived from (5). The MSC voltage

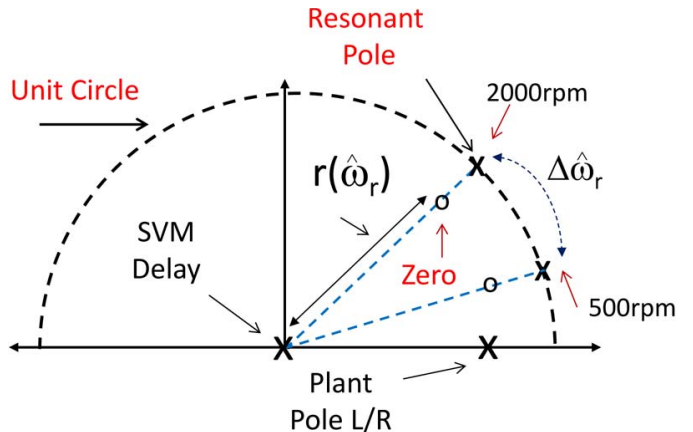

Fig. 7. Poles and zeroes of the resonant controller.

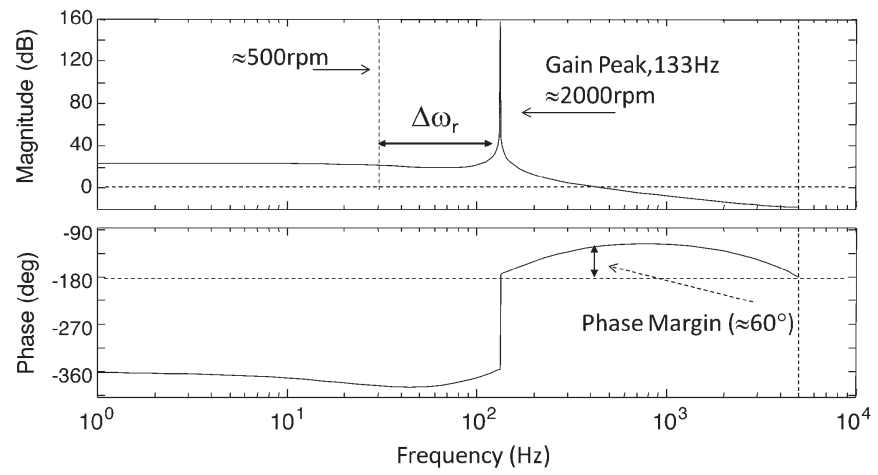

Fig. 8. Open-loop bode diagram for operation at $2000 \mathrm{r} / \mathrm{min}$.

vector $\underline{v}_{c}$ is obtained at the output of a self-tuning resonant controller (block labeled " $R C$ " in Fig. 6) whose transfer function is

$$
R C(z)=K_{r} \frac{\left(z-r\left(\widehat{\omega}_{r}\right) e^{j \widehat{\omega}_{r} T_{s}}\right)\left(z-r\left(\widehat{\omega}_{r}\right) e^{-j \widehat{\omega}_{r} T_{s}}\right)}{\left(z-e^{j \widehat{\omega}_{r} T_{s}}\right)\left(z-e^{-j \widehat{\omega}_{r} T_{s}}\right)} .
$$

Notice that in (13), $\widehat{\omega}_{\mathrm{r}}$ is the rotational speed (in electrical $\mathrm{rad} / \mathrm{s}$ ) estimated by the MRAS observer. As demonstrated in [29], tracking of the rotational speed by an MRAS observer in a PMSG is not affected by inaccurate identification of the machine parameters, i.e., $R_{s}, L_{s}$. Therefore, if the rotational speed changes relatively slowly, the resonant controller of (13) is tuned to the correct frequency even if the machine parameters change. In Fig. 6, the space vector modulation (SVM) and MSC are represented as a zero-order hold (see block labeled " $\mathrm{ZOH")}$ and a delay of one sampling period.

The controller of (13) has two poles located on the unit circle (see Fig. 7) and two zeroes, relatively close to the poles, used to increase the damping coefficient of the closed loop system. In (13), $T_{s}$ is the sampling time, $K_{r}$ is the controller gain and $r\left(\widehat{\omega}_{r}\right)$ is the distance from the controller zeros to the origin. For variable-speed operation of the PMSG, the poles of (13) are moved along the unit circle in order to track, with zero steadystate error, the reference currents of (5) (see $\Delta \widehat{\omega}_{r}$ in Fig. 7).

In this paper, the values of $K_{r}$ and $r\left(\widehat{\omega}_{r}\right)$ have been tuned using Bode diagrams and Evan's root locus at different operating points. For instance, in Fig. 8 the open-loop Bode diagram, considering operation of the PMSG at $\approx 2000 \mathrm{r} / \mathrm{min}$, is shown. 


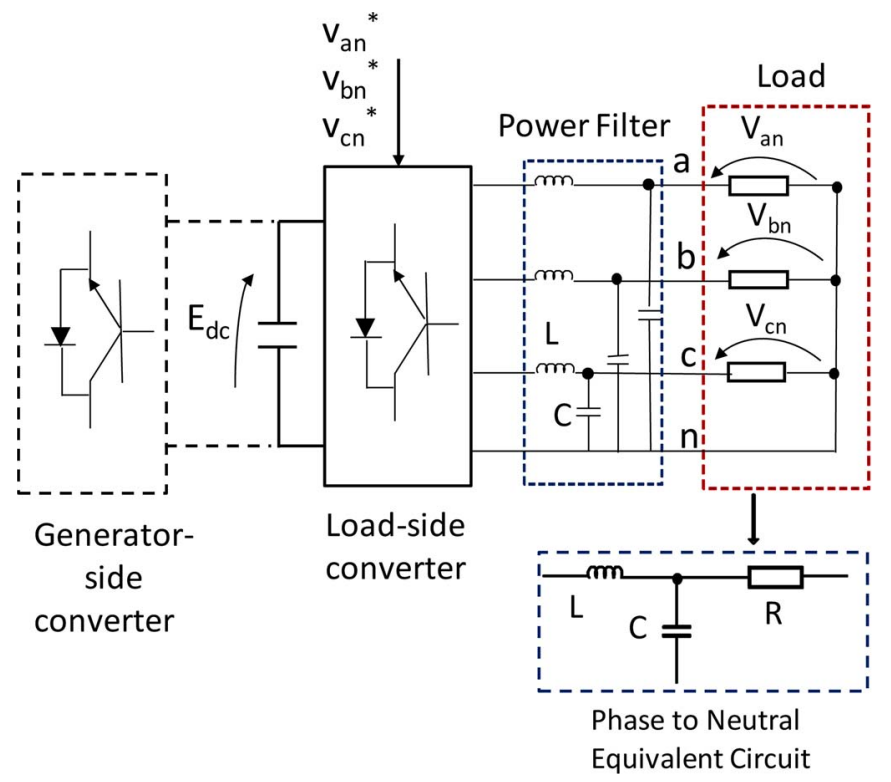

Fig. 9. LSC feeding an unbalanced linear/nonlinear load.

The control system has been designed to obtain a phase margin of $\approx 60^{\circ}$ at this operating point with a current control system bandwidth of $\approx 60-65 \mathrm{~Hz}$.

From the analytical and experimental work, and considering the parameters of the experimental system presented in the Appendix, it has been concluded that for most of the operating range, an almost fixed value of $r\left(\widehat{\omega}_{r}\right) \approx 0.95$ produces a good dynamic response. However, for a relatively low speed (close to $500 \mathrm{r} / \mathrm{min}$ ), the plant pole is closer to the poles and zeroes of the RC (see Fig. 7) and the value of $r\left(\widehat{\omega}_{r}\right)$ has to be changed in order to maintain a good dynamic performance. This approach is simple to implement and produces a good result considering that the PMSG acceleration is relatively slow. A small lookup table or similar implementation methodology can be used to obtain the value of $r\left(\widehat{\omega}_{r}\right)$.

Expanding (13), the $z$-plane transfer function is obtained as

$$
R C(z)=K_{r} \frac{\left(z^{2}-2 r\left(\widehat{\omega}_{r}\right) \cos \left(\widehat{\omega}_{r} T_{s}\right) z+r\left(\widehat{\omega}_{r}\right)^{2}\right)}{\left(z^{2}-2 \cos \left(\widehat{\omega}_{r} T_{s}\right) z+1\right)} .
$$

Using (14) the self-tuning resonant controller can be implemented in real time using a digital signal processor (DSP).

\section{Control of the Load Side Converter}

In order to feed a stand-alone load and provide a path for the circulation of zero-sequence currents, the LSC has 4 legs at the output (see Fig. 9). Resonant controllers are used to regulate the load phase-to-neutral voltages $\left(v_{a n}, v_{b n}, v_{c n}\right)$. It is assumed that the output frequency is constant; therefore, the LSC resonant controllers do not require frequency adaptation. The approach is essentially the same as that discussed in [5]-[7] for a four-leg matrix converter; thus, only a brief treatment is given here.

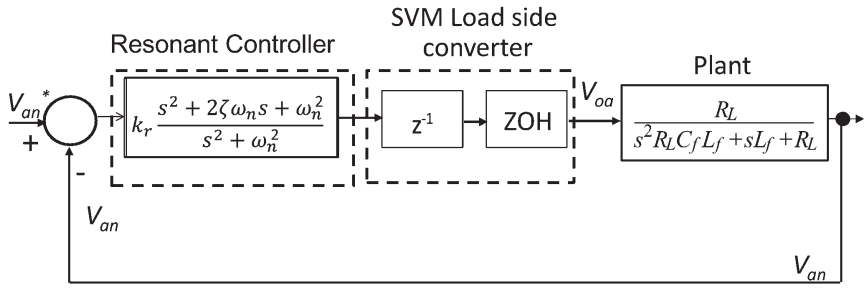

Fig. 10. Resonant control system for the LSC. Only one phase is shown.

Assuming a resistive load, the transfer function relating the phase to neutral voltage of the load to that at the output of the LSC is

$$
\frac{v_{a n}(s)}{v_{o a}(s)}=\frac{R_{L a}}{s^{2} R_{L a} C_{f} L_{f}+s L_{f}+R_{L a}}
$$

where $v_{a n}$ is the load voltage and $v_{o a}$ is the output voltage of the LSC; $R_{L a}$ is the load resistance and $C_{f}, L_{f}$ are the capacitance and inductance of the second-order output filter, respectively. A resistive load has been assumed in (15); however, the control system presented in this work can be used with both leading and lagging power factor loads. Substituting $R_{L b}$ and $R_{L c}$ for $R_{L a}$, transfer functions similar to (15) are obtained for the voltages $v_{b n}$ and $v_{c n}$ in terms of $v_{o b}$ and $v_{o c}$.

The resonant control system is designed for the worst case operating point, i.e., when there is no load connected to the output of the power filter, and the transfer function of (15) is

$$
\frac{v_{a n}(s)}{v_{a n}(s)}=\frac{1}{s^{2} C_{f} L_{f}+1}
$$

in this case, the damping coefficient of the second-order system is $\zeta=0$ and the poles of (16) are located on the $j \omega$ axis. Using (16), the control system shown in Fig. 10 is designed and implemented.

For the control system shown in Fig. 10, only one RC per phase is used. However, if the output load is strongly nonlinear, multiple resonant controllers could be required to supply voltages with low harmonic distortion to the load.

In the experimental work discussed in this paper, the control of the LSC is realized using a single RC per phase when the four-leg front-end converter is feeding linear loads. For loads with strong nonlinear behavior, three controllers per phase are implemented for the regulation of the load voltage (see Section VI). A full discussion of the issues related to the implementation of multiple-order fixed-frequency resonant controllers is considered outside the scope of this paper and the interested reader is referred elsewhere [5], [7], [34].

\section{FeEdforward Compensation Algorithm}

The PMSG stator current control system is augmented with a feedforward compensation term (see $i_{\mathrm{ff}}$ in Fig. 3) improving the dynamic response of the system when fast variations in the load fed by the LSC are produced. The feedforward algorithm is based on input/output power balancing. 
Assuming that the load voltage is well regulated and balanced, the instantaneous LSC output power is calculated as

$$
P_{\text {out }}=\operatorname{Re}\left(k_{\alpha \beta} \underline{v}_{L} \underline{i}_{o}^{c}\right)
$$

where the superscript " $c$ " is the complex conjugate operator, $\underline{v}_{L}$ is the load-voltage vector (see $v_{a n}, v_{b n}, v_{c n}$ in Fig. 9) and $\underline{i}_{o}$ is the LSC output current vector. Expanding (17) $P_{\text {out }}$ is obtained as

$$
P_{\text {out }}=\left[k_{\alpha \beta} v_{L} e^{j \omega_{e} t}\left(\sum_{k} i_{k} e^{j\left(\omega_{e} k t+\theta_{k}\right)}+\sum_{h} i_{h} e^{-j\left(\omega_{e} h t+\theta_{h}\right)}\right)^{c}\right]
$$

which can be rewritten as

$P_{\text {out }}=\left[k_{\alpha \beta} v_{L}\left(\sum_{k} i_{k} e^{j\left((1-k) \omega_{e} t+\theta_{k}\right)}+\sum_{h} i_{h} e^{j\left((h+1) \omega_{e} t+\theta_{h}\right)}\right)\right]$.

With $k, h \geq 1$. In (18)-(19), the index " $k$ " is used to denote the positive-sequence LSC output currents, and " $h$ " is used for the negative sequence components. It is assumed that $\left(\theta_{k}, \theta_{h}\right)$ are arbitrary phase angles.

Neglecting the losses, the power balance in the seven-leg converter can be written as

$$
\begin{aligned}
\operatorname{Re}\left(k_{\alpha \beta} v_{M} e^{j \omega_{r} t} \underline{i}_{M}\right)= & \frac{1}{2} C \frac{d E_{\mathrm{dc}}^{2}}{d t} \\
& +\operatorname{Re}\left[k _ { \alpha \beta } v _ { L } \left(\sum_{k} i_{k} e^{j\left((1-k) \omega_{e} t+\theta_{k}\right)}\right.\right. \\
& \left.\left.\quad+\sum_{h} i_{h} e^{j\left((h+1) \omega_{e} t+\theta_{h}\right)}\right)\right]
\end{aligned}
$$

where the term at the left-hand side of (20) is the power supplied by the PMSG and the term $(1 / 2) C\left(d E_{\mathrm{dc}}^{2} / d t\right)$ is the instantaneous power absorbed or supplied by the dc-link capacitor bank $C$.

From (20), a feedforward term can be calculated in order to improve the regulation of the dc-link voltage $E_{\mathrm{dc}}$. However, it is relatively simple to demonstrate that the instantaneous power absorbed/supplied by the dc-link capacitance $C$ cannot be driven to zero without producing harmonic distortion in the PMSG stator current when the LSC feeds an unbalanced nonlinear load. Therefore, some voltage variation has to be allowed in $E_{\mathrm{dc}}$, which can be obtained using

$$
\begin{aligned}
E_{\mathrm{dc}} \frac{d E_{\mathrm{dc}}}{d t}=\frac{1}{C} R e\left[k _ { \alpha \beta } v _ { L } \left(\sum_{k} i_{k} e^{j\left((1-k) \omega_{e} t+\theta_{k}\right)}\right.\right. \\
\left.\left.+\sum_{h} i_{h} e^{j\left((h+1) \omega_{e} t+\theta_{h}\right)}\right)\right](k>1) .
\end{aligned}
$$

Equation(21) can be useful for designing the dc-link capacitor bank, considering the expected load characteristics.

Harmonic distortion of the stator currents are not produced when the power generated by the PMSG is balanced with the dc instantaneous power produced by the positive sequence of the fundamental load current. Therefore, replacing $v_{M} \approx \psi_{m} \widehat{\omega}_{r}$ a

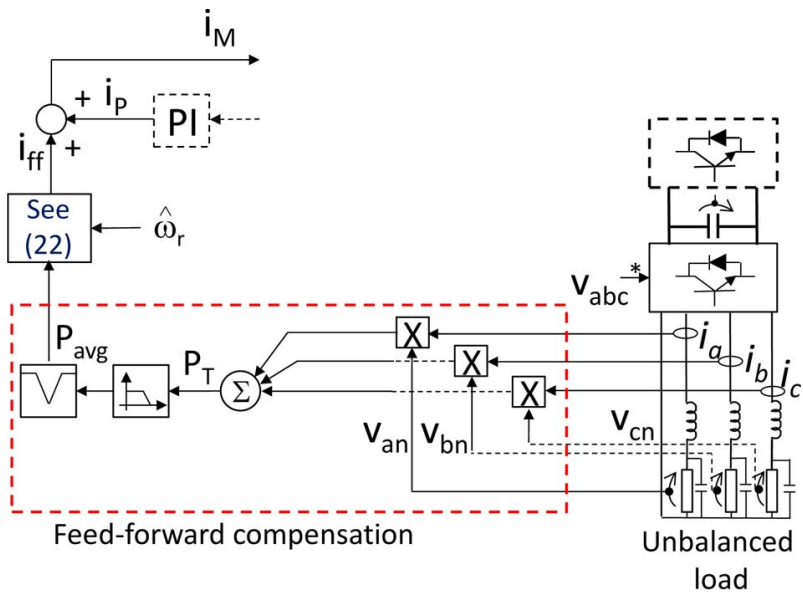

Fig. 11. Feedforward compensation system.

feedforward compensation current can be obtained calculating the term $\left|\underline{i}_{M}\right|$ in (20) as

$$
\left|\underline{i}_{M}\right|=i_{\mathrm{iff}}=\frac{P_{\mathrm{avg}}}{k_{\alpha \beta} \psi_{m} \widehat{\omega}_{r} \cos \left(\theta_{\mathrm{ph}}\right)}
$$

where $P_{\text {avg }}$ is the dc component (i.e., obtained using $k=1$, $i_{h}=0$ in (21)) of the load power.

The proposed feedforward control system is shown in Fig. 11. The power $P_{\text {avg }}$ is calculated using

$$
\begin{aligned}
& P_{\text {avg }} \\
& =\left(v_{a n} i_{o a}+v_{b n} i_{o b}+v_{c n} i_{o c}\right) \frac{\prod_{m}\left(s^{2}+m^{2} \omega_{e}^{2}\right)}{\prod_{m}\left(s^{2}+4 \zeta m \omega_{e} s+m^{2} \omega_{e}^{2}\right)} .
\end{aligned}
$$

The term at the right of (23) represents a cascade of notch filters tuned at $m \omega_{e}$, where $\omega_{e}$ is the output frequency. If the load is unbalanced but linear, only one notch filter is required tuned at $2 \omega_{e}$. If the load is nonlinear, additional notch filters are required to eliminate the power pulsations due to the current distortion.

Fig. 11 shows the implementation of the feedforward compensation term. The output power is calculated using measurements of the phase to neutral load voltages and LSC output currents. From these measurements, the average power $P_{\text {avg }}$ is calculated using (23). Because of simplicity, only one notch filter is shown in Fig. 11. An additional low-pass filter is used to eliminate the harmonics produced by the switching of the insulated-gate bipolar transistor (IGBT) devices.

Interconnection of the control systems, as discussed in the previous sections, is shown in Fig. 12.

\section{EXPERIMENTAL WORK}

The control system of Fig. 12 has been experimentally implemented (see Fig. 13) using a DSP-based control board and an FPGA, the latter providing the switching signals for the 14 IGBT gate drivers. Data acquisition uses 20 analog-todigital channels of 14 bits, $1 \mu$ s conversion time each, interfaced to the DSP. Additionally, two digital oscilloscopes, operating simultaneously in single shot mode (with sampling frequencies 


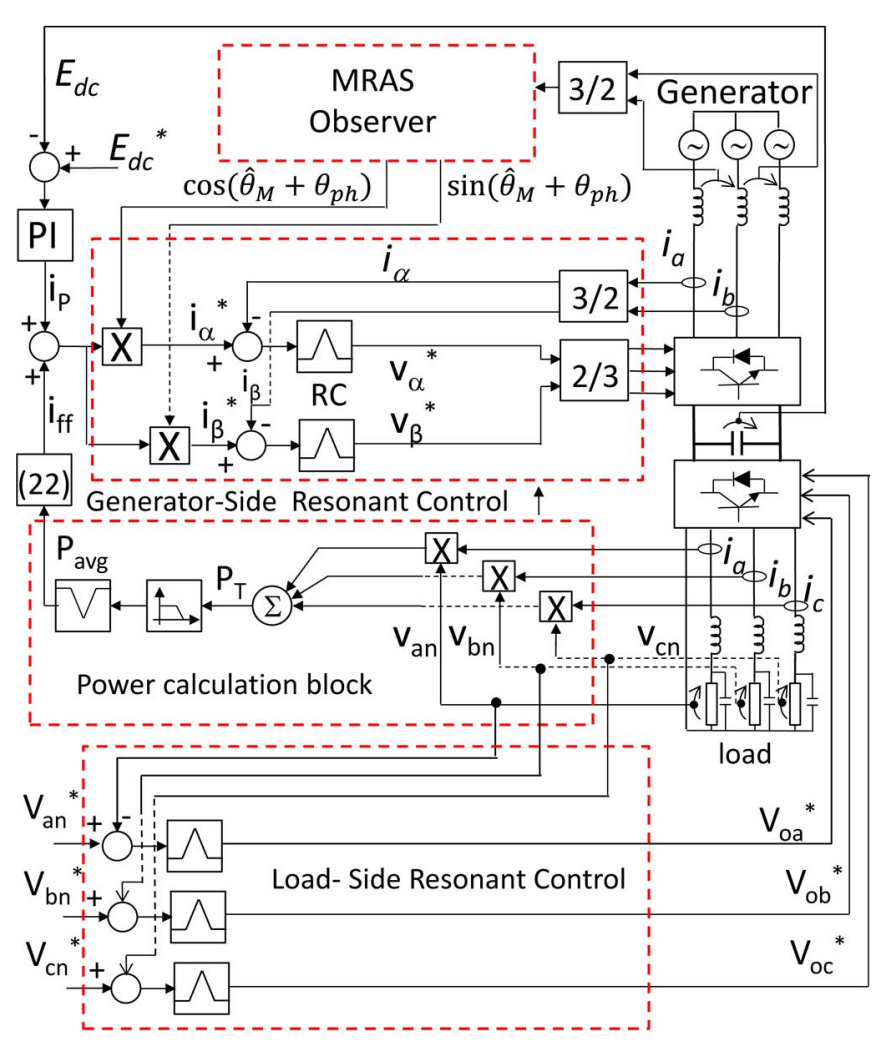

Fig. 12. Proposed control system for the seven-leg converter.

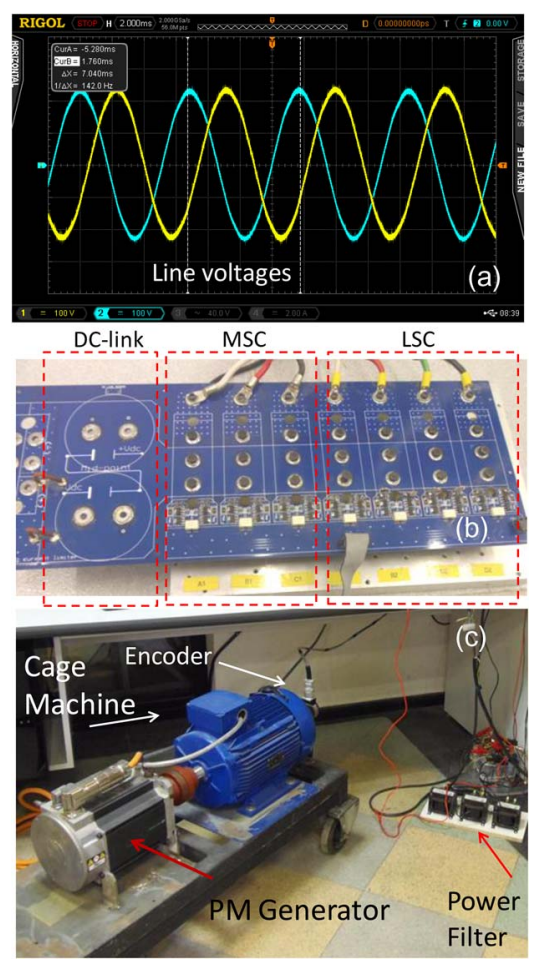

Fig. 13. (a) Two line to line voltages for the PMSG operating at $2150 \mathrm{r} / \mathrm{min}$ (b) seven-leg converter designed and implemented in this work. (c) Eight-pole PMSG and two-pole cage machine.

of $5 \mathrm{MHz}$ ) have been used in some of the experimental tests to store the current and voltages of the input and output side of the seven-leg converter. Hall-effect transducers are used to measure
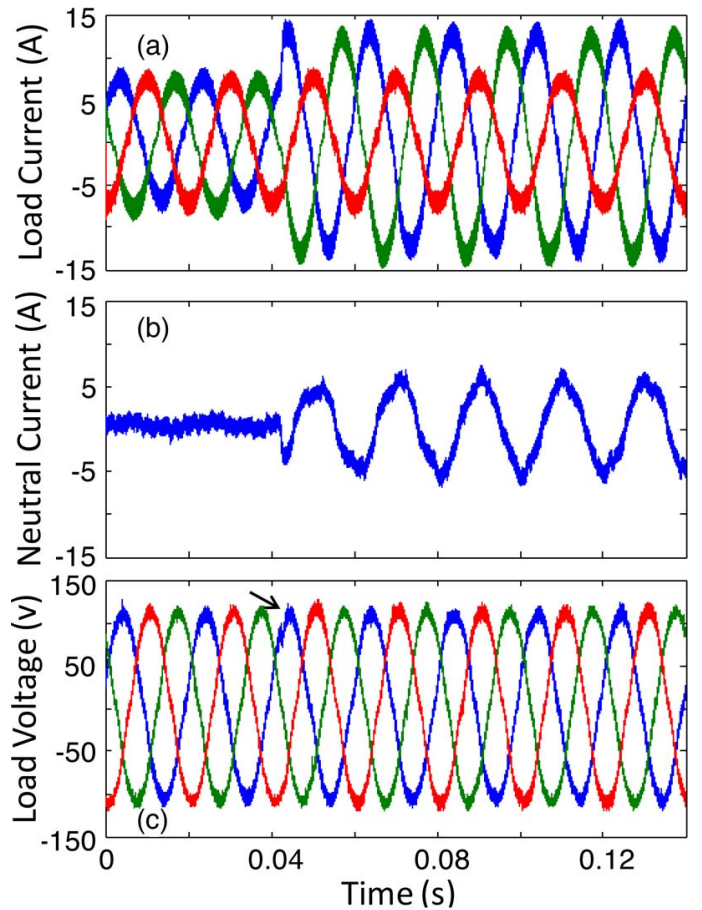

Fig. 14. Response of the LSC control systems for an unbalanced load step in two of the phases. (a) LSC output currents. (b) LSC neutral current. (c) Load voltages.

the input currents, input voltages and output load voltages. A switching frequency of $10 \mathrm{kHz}$ has been used to implement the SVM algorithms.

For the experimental tests a Control Techniques, $4 \mathrm{~kW}$, $2000 \mathrm{r} / \mathrm{min}, 8$ pole PMSG with surface mounted magnets is used. This PMSG supplies a sinusoidal voltage waveform with a total harmonic distortion (THD) of less than $1.1 \%$ [the PMSG voltage waveforms are shown in Fig 13(a)]. The parameters of the PMSG are given in Table I in the Appendix. The prime mover is a two-pole, 2910-r/min, and 5-kW cage machine. A commercial inverter is used to drive the cage machine using V/F control. The machines are shown in Fig. 13(c). The position encoder has not been used to implement the control strategies.

A seven-leg power converter has been designed and implemented for the experimental validation of the proposed control system. The PCB is shown in Fig. 13(b). Each leg has been implemented using a 1200-V 35-A dual IGBT switch Infineon BSM35GB120DN2 device. The experimental system is controlled using a Texas Instruments TMS320C6713 DSP. A daughter board with an ACTEL FPGA is used to implement the PWM generation and for interfacing the A/D, D/A converters to the DSP. A $3 \phi$ resistor bank with resistor taps of $10.7 \Omega$ and $14.7 \Omega$ is used for the load. An electronic relay controlled using one of the D/A output channels is used to implement the loadstep variations presented here.

Figs. 14 and 15 show the control system performance for an unbalanced load step. Before the load step the system is operating with a dc-link voltage $E_{\mathrm{dc}}=325 \mathrm{~V}$, a load voltage of $115 \mathrm{~V}$ peak, $\omega_{r}=1650 \mathrm{r} / \mathrm{min}$ and a balanced LSC output current of $5.3 \mathrm{~A}(\mathrm{rms})$. At $\mathrm{t} \approx 42 \mathrm{~ms}$ additional resistors are 


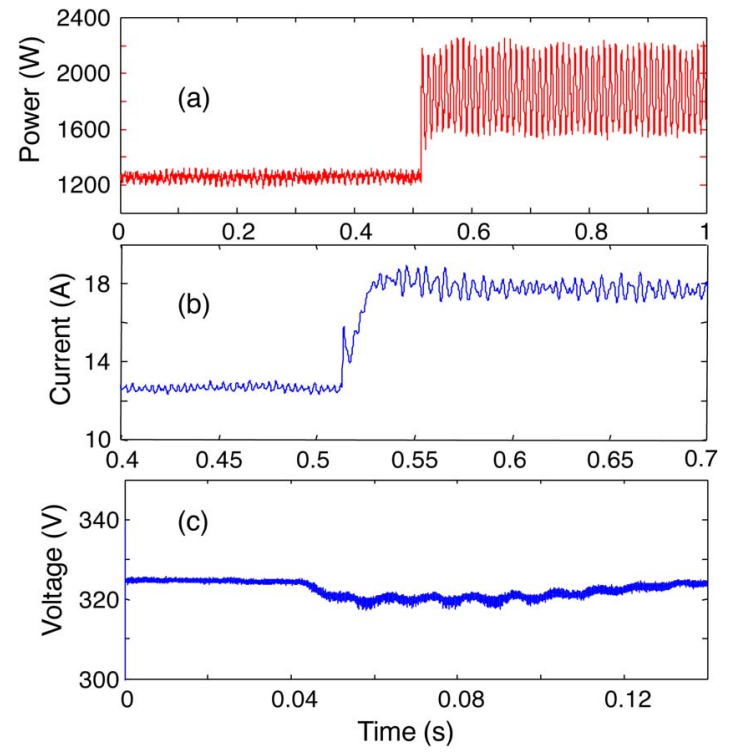

Fig. 15. (a) $3 \phi$ output power. (b) Feedforward compensation current. (c) DC-link voltage.

connected increasing the current to $12.4 \mathrm{~A}$ (rms) in two of the phases. The output currents $i_{a}, i_{b}$ and $i_{c}$ are shown in Fig. 14(a). The neutral current, with the presence of zero-sequence components, is shown in Fig. 14(b). Finally, Fig. 14(c) shows the load voltage, which has a small perturbation when the load impact is applied; this is eliminated in less than $5 \mathrm{~ms}$ (a quarter of a cycle) by the load-side RCs.

Fig. 15 shows more experimental results corresponding to the unbalanced load step of Fig. 14. Fig. 15(a) shows the $3 \phi$ output power. Before the unbalanced load step, the power is $1.27 \mathrm{~kW}$ without oscillations. After the load step, the mean output power is about $2 \mathrm{~kW}$ with a relatively large $100-\mathrm{Hz}$ component. Using a digital notch filter tuned at $100 \mathrm{~Hz}$ and a first-order digital low-pass filter tuned at $50 \mathrm{~Hz}$ [see Figs. 11, 12, and (23)], the feedforward current $i_{\mathrm{ff}}$ is calculated by the DSP using (22) and (23) and depicted in Fig. 15(b). As discussed in Section V, this current is fed-forward to the stator current control system, to improve the dynamic response of the dc-link voltage regulation.

In Fig. 15(c) the dc-link voltage is shown. With feedforward compensation, the dip is only $\approx 6 \mathrm{~V}$. Notice that the dc-link has a $100 \mathrm{~Hz}$ oscillation after the unbalanced load step is applied. As discussed in Section $\mathrm{V}$, the controller has not been designed to compensate the ac ripple in the dc-link voltage, to avoid distortion in the PMSG stator currents.

Notice that Fig. 15(c) has a different time scale. In Fig. 15(a) and (b) signals internally calculated by the DSP are shown. Fig. 15(c) shows a dc voltage signal that is captured by the digital scope.

Fig. 16(a) shows the PMSG stator current corresponding to the test depicted in Figs. 14 and 15. The input current has a frequency of about $110 \mathrm{~Hz}$ with virtually no distortion. For this case, the current is regulated with $\theta_{\mathrm{ph}} \approx 0$ (see Fig. 3). Fig. 16(b) and (c) show the $\alpha-\beta$ tracking error of the selftuning resonant control system. For the whole test, the tracking error is low, with a peak below 0.75 A produced when the
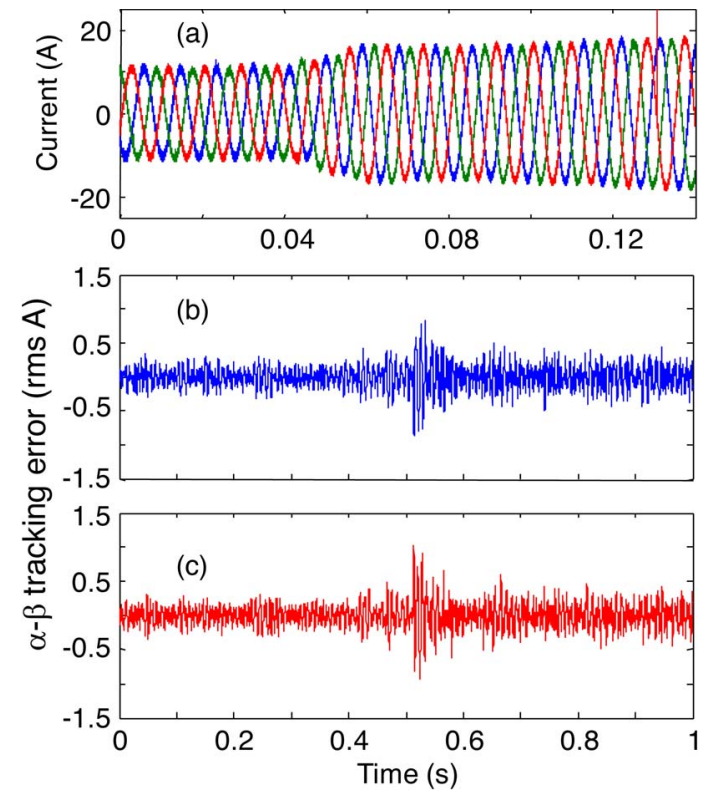

Fig. 16. Input currents. (a) Instantaneous input current. (b) $\alpha$-axis (rms) stator current tracking error. (c) $\beta$-axis (rms) stator current tracking error.

current $i_{\mathrm{ff}}$ has a fast variation from $i_{\mathrm{ff}} \approx 12 \mathrm{~A}$ to $i_{\mathrm{ff}} \approx 18 \mathrm{~A}$ (peak current) at $\mathrm{t} \approx 0.5 \mathrm{~s}$.

The control system of Fig. 12 has been tested considering a relatively fast ramp speed variation. For this test, the experimental results are shown using the effective (rms) current of each phase. This methodology is preferred because of the problems associated with displaying $d-q$ currents under unbalanced operation. Moreover, the zero-sequence components are not reflected in the $d-q$ signals.

The LSC (rms) output currents are calculated using a digital implementation of

$$
i_{\mathrm{rms}}=\sqrt{\frac{1}{T} \int i^{2}(t) d t} .
$$

A low-pass filter is used to calculate the root mean square value of (24).

Fig. 17 shows results for a speed ramp variation between $\omega_{r} \approx 800 \mathrm{r} / \mathrm{min}$ to $\approx 1500 \mathrm{r} / \mathrm{min}$. At $\mathrm{t} \approx 2 \mathrm{~s}$ an unbalanced load step is applied to two of the phases and disconnected at $t \approx 7.3 \mathrm{~s}$. Fig. 17(a) shows the estimated rotational speed $\widehat{\omega}_{r}$ and the reference speed $\omega_{r}^{*}$ sent to the commercial inverter. In Fig. 17(b) and (c) the LSC output currents $i_{a}, i_{b}$, and $i_{c}$ are shown. Notice that the effective current is constant in phase $c$ and that the unbalanced load-step variations are applied to phases $b$ and $c$. Finally, Fig. 17(d) shows the zero-sequence components circulating through the $4^{\text {th }}$ leg, used as a neutral connection in this application.

Fig. 18 shows additional signals corresponding to the ramp speed variation test shown in Fig. 17. Fig. 18(a) shows the magnitude of the PMSG $d-q$ stator current. Because the system is feeding a constant load at the output, the PMSG power current is proportional to $1 / \omega_{r}$. Fig. 18(b) shows the instantaneous power measured at the output. As explained before, this power 


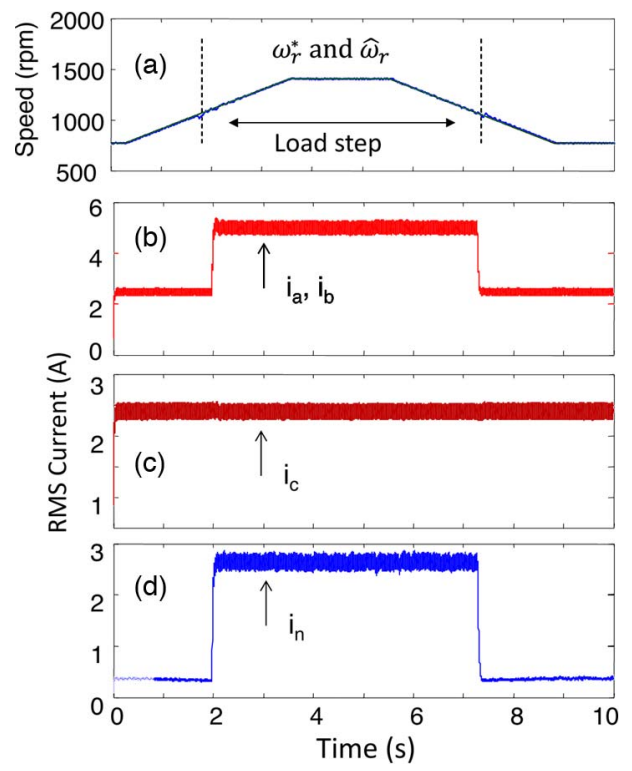

Fig. 17. Control system performance for a ramp step variation. (a) Reference $\left(\omega_{r}^{*}\right)$ and estimated $\left(\widehat{\omega}_{r}\right)$ rotational speeds. (b) LSC output currents $i_{a}$ and $i_{b}$. (c) LSC output currents $i_{c}$. (d) Neutral current.
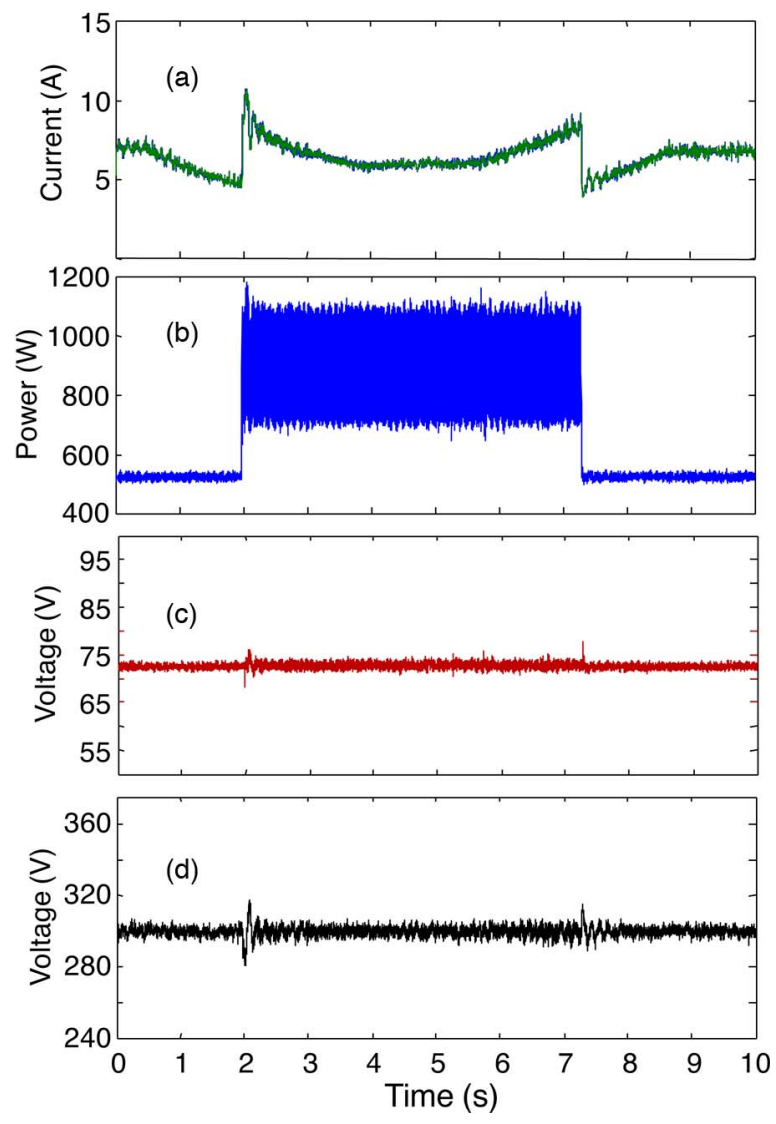

Fig. 18. Control system performance corresponding to the ramp step variation of Fig. 17. (a) PMSG stator current. (b) Instantaneous load power. (c) Magnitude (obtained from $d-q$ coordinates) of the load voltage. (d) DC-link voltage.

is filtered and the feedforward compensating current is obtained using (22) and (23). Fig. 18(c) shows the phase to neutral load voltage. Because of the boost capability of the MSC, the load

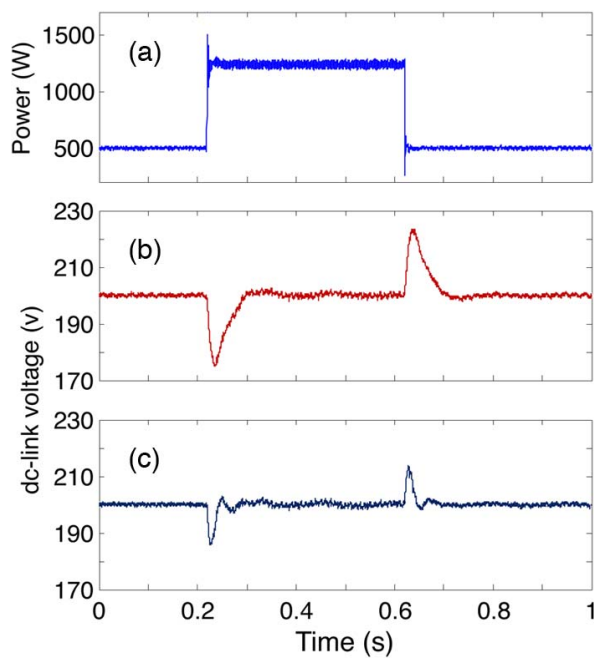

Fig. 19. Performance of the feedforward compensation algorithm. (a) $3 \phi$ balanced load step. (b) DC-link voltage variation without considering feedforward compensation. (c) DC-link voltage variation considering feedforward compensation.

voltage can be regulated to a value, which is higher than the internal voltage (a phase voltage of $\approx 40 \mathrm{~V}$ at $800 \mathrm{r} / \mathrm{min}$ ). This is an advantage compared with previous implementations (see [5]). Notice that the load voltage is well regulated with a dip and an overshoot of less than 5 V. Finally, Fig 18(d) shows the dc-link voltage. For this test, the dc-link voltage is well regulated $\left(E_{\mathrm{dc}}^{*}=300 \mathrm{~V}\right)$ with a dip and overshoot of less than $19 \mathrm{~V}\left(\approx 6 \%\right.$ of $\left.E_{\mathrm{dc}}\right)$.

The performance of the feedforward compensation algorithm, for the regulation of the dc-link voltage, is shown in Fig. 19. The system is operating with a rotational speed of $750 \mathrm{r} / \mathrm{min}$, the dc-link voltage is regulated to $200 \mathrm{~V}$ and a $3 \phi$ balanced load step is applied. Fig. 19(a) shows the output power variation from 500 to $1250 \mathrm{~W}$. Fig. 19(b) shows the response of the dc-link control system without the feedforward term of (22). The nominal voltage is $200 \mathrm{~V}$ and the dip and the overshoot are about $25 \mathrm{~V}$ for a dc-link capacitor bank of about $1600 \mu \mathrm{F}$. When the feedforward term is included [Fig. 19(c)] the dip and the overshoot are reduced to $15 \mathrm{~V}$ and the settling time (considering a $2 \%$ band) is reduced from $\approx 90 \mathrm{~ms}$ to $\approx 20 \mathrm{~ms}$ for the same power step.

In Fig. 20 the performance of the proposed control system, for a nonlinear load step, is shown. The system is operating with a balanced load of about $1300 \mathrm{~W}, 1650 \mathrm{r} / \mathrm{min}$, when at $\mathrm{t} \approx 58 \mathrm{~ms}$ a nonlinear load composed of a $14.7 \Omega$ resistor, in series with a rectifier diode, is applied to phase $a$. For this case, additional resonant controllers, tuned to eliminate dc signals and thirdorder harmonics are implemented in the LSC control system to regulate the load voltage. The implementation of high-order resonant controllers is discussed in [5], [9], [34], [35].

Fig. 20(a) shows the LSC output currents $i_{a}, i_{b}, i_{c}$. Before the nonlinear step, the current in phase-a has negligible distortion. After the nonlinear load step the current in phase-a is increased with a noticeable dc component whose magnitude is $\approx 32 \%$ with respect to the fundamental. Moreover, after the step, the second and the fourth harmonics are also present in $i_{a}$ with 

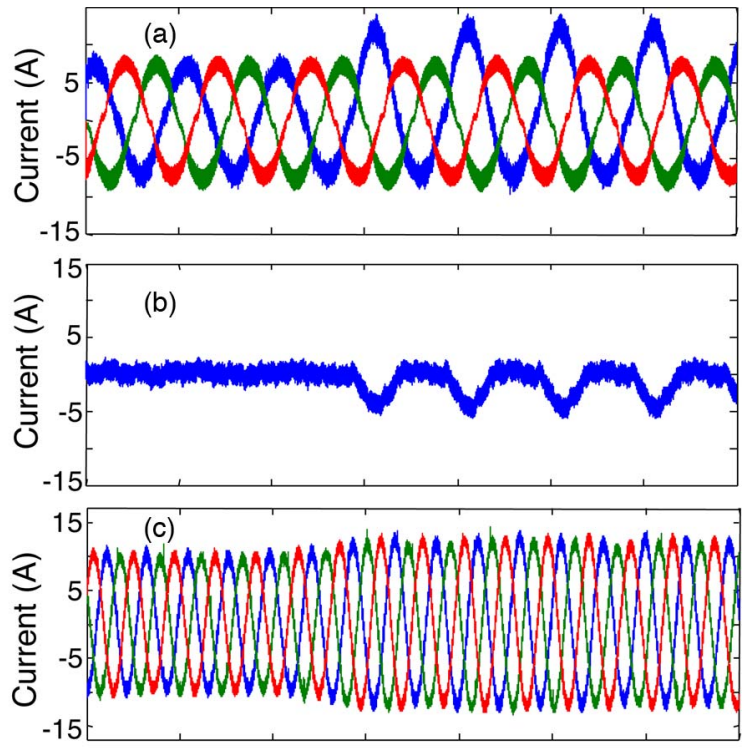

$-15$

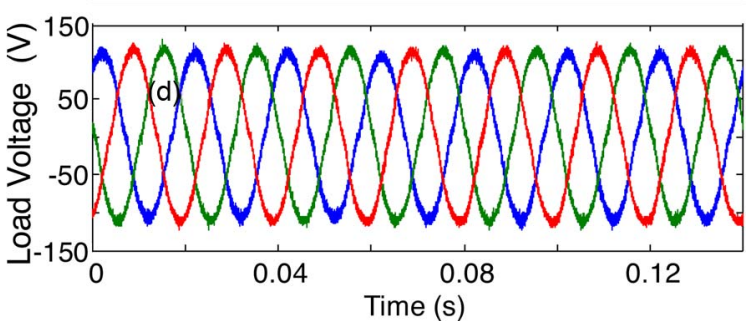

Fig. 20. Control system performance considering a nonlinear load step. (a) LSC output currents $i_{a}, i_{b}$ and $i_{c}$. (b) Neutral current. (c) PMSG stator currents. (d) Load voltage.

magnitudes of $\approx 11 \%$ and $3 \%$, respectively. Fig. 20(b) shows the zero-sequence current components (produced by the nonlinear load) that circulate in the neutral leg.

Fig. 20(c) shows the stator current, which is well regulated with little distortion. Finally, the load voltage is shown in Fig. 20(d). As shown in this graphic, the load voltage is well regulated and the effects of the nonlinear step are negligible. Moreover, the high-order resonant controller reduces the distortion in the load voltage.

\section{CONCLUSION}

A control method for a seven-leg back-to-back VSI has been presented. It is based on resonant controllers and a feedforward compensation term. A frequency adaptive control system for the regulation of the PMSG stator current has been presented and experimentally validated. A control system topology for the regulation of the dc-link voltage, avoiding distortion in the generator current, has been analyzed in this work. A feedforward compensation algorithm has been proposed that is effective in improving the dynamic performance of the dc-link voltage control.

The proposed control system has been tested considering balanced, unbalanced and nonlinear load operating under variable/fixed rotational speed. The results have shown the good performance achieved with the proposed control methodology.

\section{APPENDIX}

TABLE I

PARAMETERS OF THE PMSG

\begin{tabular}{|c|c|}
\hline Nominal rotational speed & $2000 \mathrm{rpm}$ \\
\hline Nominal Power & $4 \mathrm{~kW}$ \\
\hline Maximum Rotational Speed & $2800 \mathrm{rpm}$ \\
\hline Torque constant & $1.4 \mathrm{Nm} / \mathrm{A}$ \\
\hline Nominal Torque & $20 \mathrm{Nm}$ \\
\hline Voltage Constant & $85.5 \mathrm{~V} / \mathrm{Krpm}$ \\
& $($ line voltage) \\
\hline Recommended Drive PWM & $220 / 240 \mathrm{~V}$ \\
\hline Voltage & $($ line voltage) \\
\hline Stator Inductance & $\approx 4 \mathrm{mH}$ \\
\hline Stator Resistance & $\approx 0.2 \Omega$ \\
\hline Output Waveform & Sinusoidal \\
& $(\mathrm{THD}<1.1 \%$ ) \\
\hline
\end{tabular}

TABLE II

PARAMETERS OF THE EXPERIMENTAL SYSTEM

\begin{tabular}{|c|c|}
\hline Switching Frequency & $10 \mathrm{kHz}$ \\
\hline Output Filter Inductance & $L_{f}=2.5 \mathrm{mH}$ \\
\hline Output Filter Capacitance & $C_{f}=40 \mu \mathrm{F}$ \\
\hline Output frequency & $50 \mathrm{~Hz}$ \\
\hline dc-link capacitance & $1600 \mu \mathrm{F}$ \\
\hline
\end{tabular}

\section{REFERENCES}

[1] R. Cardenas and R. Pena, "Sensorless vector control of induction machines for variable-speed wind energy applications," IEEE Trans. Energy Convers., vol. 19, no. 1, pp. 196-205, Mar. 2004.

[2] J. Leuchter, V. Refucha, Z. Krupka, and P. Bauer, "Dynamic behavior of mobile generator set with variable speed and diesel engine," in Proc. IEEE PESC, 2007, pp. 2287-2293.

[3] P. W. Wheeler et al., "A utility power supply based on a four-output leg matrix converter," IEEE Trans. Ind. Appl., vol. 44, no. 1, pp. 174-186, Jan./Feb. 2008.

[4] T. Friedli, J. W. Kolar, J. Rodriguez, and P. W. Wheeler, "Comparative evaluation of three-phase AC-AC matrix converter and voltage DC-link back-to-back converter systems," IEEE Trans. Ind. Electron., vol. 59, no. 12, pp. 4487-4510, Dec. 2012.

[5] R. Cardenas, C. Juri, R. Pena, J. Clare, and P. Wheeler, "Analysis and experimental validation of control systems for four-leg matrix converter applications," IEEE Trans. Ind. Electron., vol. 59, no. 1, pp. 141-153, Jan. 2012.

[6] R. Cardenas, R. Peña, C. Juri, P. Wheeler, and J. Clare, "Control of a matrix converter for the operation of autonomous systems," Renew. Energy, vol. 27, no. 3, pp. 1120-1129, Jul. 2012.

[7] R. Cardenas, C. Juri, R. Pena, P. Wheeler, and J. Clare, "The application of resonant controllers to four-leg matrix converters feeding unbalanced or nonlinear loads," IEEE Trans. Power Electron., vol. 27, no. 3, pp. 1120-1129, Mar. 2012.

[8] S. Ei-Barbari and W. Hofmann, "Digital control of a four leg inverter for standalone photovoltaic systems with unbalanced load," in Proc. 26th Anпи. IEEE IECON, 2000, vol. 2, pp. 729-734.

[9] M. Rashed, C. Klumpner, and G. Asher, "Repetitive and resonant control for a single-phase grid-connected hybrid cascaded multilevel converter," IEEE Trans. Power Electron., vol. 28, no. 5. pp. 2224-2234, May 2013.

[10] M. Angulo, D. A. Ruiz-Caballero, J. Lago, M. L. Heldwein, and S. A. Mussa, "Active power filter control strategy with implicit closedloop current control and resonant controller," IEEE Trans. Ind. Electron., vol. 60, no. 7. pp. 2721-2730, Jul. 2013.

[11] Y. Yang, K. Zhou, and M. Cheng, "Phase compensation resonant controller for PWM converters," IEEE Trans. Ind. Informat., vol. 9, no. 2, pp. 957-964, May 2013.

[12] K. Zhou, Y. Yang, F. Blaabjerg, and D. Wang, "Optimal selective harmonic control for power harmonics mitigation," IEEE Trans. Ind. Electron., vol. 62, no. 2. pp. 1220-1230, Feb. 2015.

[13] W.-L. Chen and J.-S. Lin, "One-dimensional optimization for proportional resonant controller design against the change in source impedance and solar irradiation in PV systems," IEEE Trans. Ind. Electron., vol. 61, no. 4. pp. 1845-1854, Apr. 2014. 
[14] T. Dragicevic, J. M. Guerrero, and J. C. Vasquez, "A distributed control strategy for coordination of an autonomous LVDC microgrid based on power-line signaling," IEEE Trans. Ind. Electron., vol. 61, no. 7. pp. 3313-3326, Jul. 2014.

[15] R. Pena, R. Cardenas, J. Proboste, J. Clare, and G. Asher, "Wind-diesel generation using doubly fed induction machines," IEEE Trans. Energy Convers., vol. 23, no. 1, pp. 202-214, Mar. 2008.

[16] M. A. Hamida, J. De Leon, A. Glumineau, and R. Boisliveau, "An adaptive interconnected observer for sensorless control of PM synchronous motors with online parameter identification," IEEE Trans. Ind. Electron., vol. 60 , no. 2 , pp. $739-748$, Feb. 2013.

[17] F. Tang, X. Zhou, L. Meng, J. M. Guerrero, and J. C. Vasquez, "Secondary voltage unbalance compensation for three-phase four-wire islanded microgrids," in Proc. 11th Int. Multi-Conf. SSD, 2014. pp. 1-5.

[18] F. Rojas-Lobos, R. Kennel, and R. Cardenas-Dobson, "3D-SV algorithm and capacitor voltage balancing in a four-leg NPC converter operating under unbalanced and nonlinear loads," in Proc. 15th EPE Appl. Conf., 2013. pp. 1-10.

[19] A. G. Yepes et al., "Effects of discretization methods on the performance of resonant controllers," IEEE Trans. Power Electron., vol. 25, no. 7, pp. 1692-1712, Jul. 2010.

[20] F. Gonzalez-Espin, I. Patrao, E. Figueres, and G. Garcera, “An adaptive digital control technique for improved performance of grid connected inverters," IEEE Trans. Ind. Informat., vol. 9, no. 2, pp. 708-718, May 2013.

[21] X. Guillaud, P. Degobert, and R. Teodorescu, "Use of resonant controller for grid-connected converters in case of large frequency fluctuations," in Proc. Eur. Conf. Power Electron. Appl., 2007, vol. 1, pp. 1-8.

[22] P. Degobert, G. Remy, J. Zeng, P.-J. Barre, and J.-P. Hautier, "High performance control of the permanent magnet synchronous motor using selftuning resonant controllers," in Proc. 38th SSST, 2006, pp. 382-386.

[23] C. Xia, Z. Wang, T. Shi, and X. He, “An improved control strategy of triple line-voltage cascaded voltage source converter based on proportionalresonant controller," IEEE Trans. Ind. Electron., vol. 60, no. 7, pp. 2894-2908, Jul. 2013.

[24] R. Cardenas, R. Pena, J. Clare, G. Asher, and J. Proboste, "MRAS observers for sensorless control of doubly-fed induction generators," IEEE Trans. Power Electron., vol. 23, no. 3, pp. 1075-1084, May 2008.

[25] T. Halkosaari, "Speed Sensorless vector control of a redundant permanent magnet wind power generator," in Proc. IEEE Int. Symp. Ind. Electron., Jun. 2007, pp. 2595-2600.

[26] D. Xiao and M. F. Rahman, "Sensorless direct torque and flux controlled IPM synchronous machine fed by matrix converter over a wide speed range," IEEE Trans. Ind. Informat., vol. 9, no. 4. pp. 1855-1867, Nov. 2013.

[27] F. Wang et al., "Encoderless finite-state predictive torque control for induction machine with a compensated MRAS," IEEE Trans. Ind. Informat., vol. 10, no. 2. pp. 1097-1106, May 2014.

[28] R. Peña, R. Cardenas, J. Proboste, G. Asher, and J. Clare, "Sensorless control of doubly-fed induction generators using a rotor-current-based MRAS observer," IEEE Trans. Ind. Electron., vol. 55, no. 1, pp. 330-339, Jan. 2008.

[29] S. Po-ngam and S. Sangwongwanich, "Stability and dynamic performance improvement of adaptive full-order observers for sensorless PMSM drive," IEEE Trans. Power Electron., vol. 27, no. 2, pp. 588-600, Feb. 2012.

[30] C. Schauder, "Adaptive speed identification for vector control of induction motors without rotational transducers," IEEE Trans. Ind. Appl., vol. 28, no. 5, pp. 1054-1061, Sep./Oct. 1992.

[31] L. Zhao, J. Huang, H. Liu, B. Li, and W. Kong, "Second-order slidingmode observer with online parameter identification for sensorless induction motor drives," IEEE Trans. Ind. Electron., vol. 61, no. 10, pp. 5280-5289, Oct. 2014.

[32] S. Basak, A. V. Ravi Teja, C. Chakraborty, and Y. Hori, "A new model reference adaptive formulation to estimate stator resistance in field oriented induction motor drive," in Proc. 39th Annu. IEEE IECON, Nov. 2013, pp. 8470-8475.

[33] H. Polinder, F. F. A. van der Pijl, G.-J. de Vilder, and P. J. Tavner, "Comparison of direct-drive and geared generator concepts for wind turbines," IEEE Trans. Energy Convers., vol. 21, no. 3. pp. 725-733, Sep. 2006.

[34] L. F. Alves Pereira et al., "Multiple resonant controllers for uninterruptible power supplies-A systematic robust control design approach," IEEE Trans. Ind. Electron., vol. 61, no. 3. pp. 1528-1538, Mar. 2014.

[35] M. Castilla, J. Miret, A. Camacho, J. Matas, and L. G. de Vicuna, "Reduction of current harmonic distortion in three-phase grid-connected photovoltaic inverters via resonant current control," IEEE Trans. Ind. Electron., vol. 60, no. 4, pp. 1464-1472, Apr. 2013.

[36] C. Xia, F. Zhou, Z. Wang, and X. He, "Equivalent switch circuit model and proportional resonant control for triple line-voltage cascaded voltage-source converter," IEEE Trans. Power Electron., vol. 28, no. 5, pp. 2389-2401, May 2013.

[37] J. Zeng, P. Degobert, D. Loriol, and J.-P. Hautier, "Robust design of the self-tuning resonant controller for AC current control systems," in Proc. IEEE Int. Conf. Ind. Technol., 2005, pp. 783-788.

[38] A. R. Al-Ali, G. R. Kenny, and A. B. Bonds, "Self tuning resonant circuit using a microprocessor based system," in Proc. IEEE Southeastcon, 1991, vol. 1 , pp. 138-141.

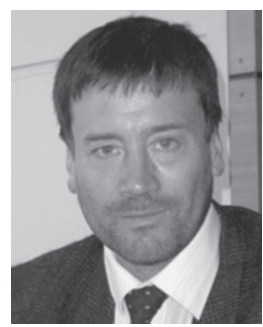

Roberto Cárdenas (S'95-M'97-SM'07) was born in Punta Arenas, Chile. He received the B.S. degree from the University of Magallanes, Punta Arenas, in 1988 and the M.Sc. and Ph.D. degrees from The University of Nottingham, Nottingham, U.K., in 1992 and 1996, respectively.

From 1989 to 1991 and 1996 to 2008, he was a Lecturer with the University of Magallanes. From 1991 to 1996, he was with the Power Electronics Machines and Control Group (PEMC group), The University of Nottingham. From 2009 to 2011, he was with the Department of Electrical Engineering, University of Santiago, Santiago, Chile. He is currently a Professor in power electronics and drives with the Department of Electrical Engineering, University of Chile, Santiago. His main interests are in control of electrical machines, variable-speed drives, and renewable energy systems.

Prof. Cárdenas was the recipient of the Best Paper Award from the IEEE TRANSACTIONS ON INDUSTRIAL ELECTRONICS in 2005.

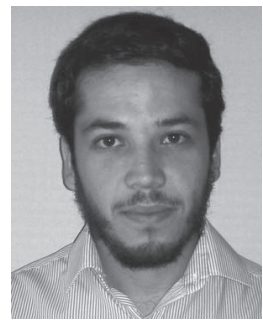

Enrique Espina was born in Santiago, Chile, in 1986. He received the B.Sc. degree in electrical engineering from the University of Santiago, Santiago, Chile, in 2012, where he is currently working toward the M.S. degree in the Department of Electrical Engineering.

His research interests include renewable generation systems, distributed generation, microgrids, and power electronics converters.

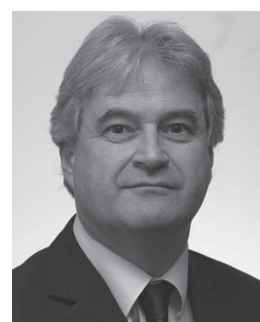

Jon Clare (M'90-SM'04) was born in Bristol, U.K. He received the B.Sc. and Ph.D. degrees in electrical engineering from The University of Bristol, Bristol.

From 1984 to 1990, he was a Research Assistant and Lecturer with The University of Bristol, involved in teaching and research in power electronic systems. Since 1990, he has been with the Power Electronics, Machines and Control Group, The University of Nottingham, Nottingham, U.K., and is currently a Professor in power electronics. His research interests are power electronic converters and modulation strategies, variable-speed drive systems, and electromagnetic compatibility.

Prof. Clare is a Member of the Institution of Engineering and Technology, U.K.

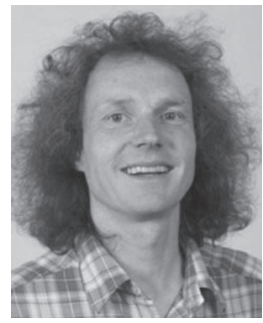

Patrick Wheeler (M'00-SM'11) received the B.Eng. [Hons] degree and the Ph.D. degree in electrical engineering for his work on matrix converters from The University of Bristol, Bristol, U.K., in 1990 and 1994, respectively.

In 1993, he moved to The University of Nottingham, Nottingham, U.K., and worked as a Research Assistant with the Department of Electrical and Electronic Engineering. In 1996, he became a Lecturer with the Power Electronics, Machines and Control Group, The University of Nottingham. Since January 2008, he has been a Full Professor with the same research group. He has published 400 academic publications in leading international conference proceedings and journals.

Prof. Wheeler is an IEEE Power Electronics Society (PELS) Member at Large and an IEEE PELS Distinguished Lecturer. 